\title{
LOS PUERTOS, LAS EXPORTACIONES Y LAS CONEXIONES MATERIALES DE ENTRE RÍOS (1958-1983)
}

\author{
The ports, exports and material connections of Entre Rios (1958-1983)
}

\author{
José Mateo* \\ https://orcid.org/0000-0001-6599-5684 \\ Maximilano Camarda** \\ https://orcid.org/0000-0002-6196-4757
}

Guadalupe Ranieri***

https://orcid.org/0000-0003-4389-9928

\section{Resumen}

En el presente trabajo nos avocamos al análisis de la actividad exportadora de los puertos de Entre Ríos entre 1958 (sin conectividad material con el continente) y 1983 (con conectividad casi plena tanto con la Argentina como con la República Oriental del Uruguay). El objetivo es determinar el impacto de las conexiones materiales (túnel y puentes) en la dinámica portuaria entrerriana. Comenzaremos con un análisis general de la participación de los puertos entrerrianos en la recaudación aduanera del período y los productos que fueron objeto de exportación para luego realizar un análisis más detallado de los procesos que fueron vividos en los trece puertos (cinco sobre el Río Uruguay y ocho sobre el Río Paraná) con actividad portuaria durante el período. La principal fuente utilizada son los Anuarios Estadísticos o Anuarios de Comercio Exterior de la Argentina publicados entre esos años.

$<$ Puertos $><$ Exportaciones $><$ Entre Ríos $><$ siglo XX $>$

\begin{abstract}
In this paper, we focus on the analysis of export activity in the ports of the province of Entre Ríos, between 1958 (when the province did not have material connection with the continent) and 1983 (Entre Ríos had almost full connectivity with both Argentina and Uruguay). The objective of the article is to determine the impact of material connections (tunnels and bridges) on the dynamics of the ports of this province. We will begin with a general analysis of the participation of Entre Ríos ports in customs mobility of this period and the products that were exported. Then, we will make an in-depth analysis of the processes that were experienced in the thirteen ports (five on Uruguay River and eight on Paraná River) with port activity during the period. The main source used is the Statistical Yearbooks or Argentina Foreign Trade Yearbooks, published between those years.
\end{abstract}

$<$ Ports $><$ Exports $><$ Entre Ríos $><$ twentieth century $>$

Recibido: 19/06/2020//Aceptado: 15/09/2020

* Consejo Nacional de Ciencia y Tecnología (CONICET). Instituto de Estudios Sociales (INES), Facultad de Ciencias Económicas, Universidad Nacional de Entre Ríos (FCECO-UNER), Argentina, jamateo@ffceco.uner.edu.ar

** Consejo Nacional de Ciencia y Tecnología (CONICET). Instituto de Estudios Sociales (INES), Facultad de Ciencias Económicas, Universidad Nacional de Entre Ríos (FCECO-UNER), Argentina, maximilianocamarda@hotmail.com

***Facultad de Ciencias Económicas, Universidad Nacional de Entre Ríos (FCECO-UNER), Argentina, guadaranieri@gmail.com 
Mateo, Camarda y Ranieri. Los puertos, las exportaciones y las conexiones materiales de Entre Ríos (1958-1983).

\section{Introducción}

La Mesopotamia argentina, como se desprende de su nombre, es un espacio con características insulares dentro del territorio argentino. Su vinculación material al continente se produjo por primera vez en 1947 al inaugurarse en puente ferroautomotor que une las ciudades de Paso de los Libres (Corrientes, Argentina) con Uruguaina (Río Grande do Sul, Brasil). Para que esta región se uniera de forma carretera al resto de la Argentina superando la barrera del Río Paraná, debió esperarse más de veinte años, hasta el 13 de diciembre de 1969 cuando fue inaugurado el túnel subfluvial que une desde entonces a las ciudades capitales provinciales de Paraná (Entre Ríos) y Santa $\mathrm{Fe}$, en la provincia homónima (Mateo \& Camarda, 2018). Muy pocos años después, en 1973 las ciudades de Barranqueras (Chaco) y Corrientes en la provincia del mismo nombre fueron unidas por el primer puente carretero sobre el río Paraná y en 1977, la región contó con otro puente que unía el sur de la provincia de Entre Ríos con el norte de Buenos Aires, el complejo Zárate Brazo Largo (Ferrer \& Rougier, 2010). A su vez, dos puentes más unieron a la provincia de Entre Ríos con la República Oriental del Uruguay. El primero une las localidades de Colón (Argentina) con la de Paysandú (ROU) inaugurado en 1975 y el segundo las de Puerto Unzué (aledaño a la ciudad de Gualeguaychú) con Fray Bentos (ROU). Finalmente, en 1976, el Río Uruguay fue surcado por una represa hidroeléctrica, Salto Grande, cuyo coronamiento contiene un tercer acceso carretero y un primero ferroviario entre Concordia (Entre Ríos) y Salto (ROU), inaugurado en 1982. En el año 2003 un nuevo puente entre las ciudades de Rosario (Santa Fe) y Victoria (Entre Ríos) completó hasta el momento la vinculación material de la provincia de Entre Ríos con el continente sobre los dos grandes ríos que dan nombre a la provincia.

Hasta el avance de estas conexiones que hicieron posible el tránsito carretero, la salida de mercancías de la región se realizaba a través de balsas, vapores, lanchas (Camarda, 2018) y los ferry boats que unían Puerto Constanza en la provincia de Entre Ríos con Zárate en el norte de la de Buenos Aires (Cusmai, 2014) e incluso con el puerto de Buenos Aires. Es decir, el camión y el ferrocarril no fueron ajenos a los flujos de exportaciones de la provincia desde su insularidad hasta su conectividad plena (Mateo, 2018), compartiendo este movimiento con el transporte fluvial en embarcaciones (vapores, con motores a explosión y barcazas).

En el presente trabajo nos avocamos al análisis de la actividad exportadora de los puertos de Entre Ríos entre 1958 ( sin conectividad material con el continente) y 1983 (con conectividad casi plena tanto con la Argentina como con la República Oriental del Uruguay). Comenzaremos con un análisis general de la participación de los puertos entrerrianos en la recaudación aduanera del período y los productos que fueron objeto de exportación para luego realizar un análisis más detallado de los procesos que fueron vividos en los trece puertos (cinco sobre el Río Uruguay y ocho sobre el Río Paraná) con actividad portuaria durante el período. La principal fuente utilizada son los Anuarios Estadísticos o Anuarios de Comercio Exterior de la Argentina publicados entre esos años. 
El análisis, además de permitirnos medir y evaluar el tráfico a través de los puertos, permite señalar cuáles eran las mercancías que utilizaban esos tráficos, en qué productos se especializaban los puertos, y de alguna manera interpretar las actividades productivas de los hinterlands de cada uno de ellos, sirve para mostrarnos si tuvo efecto el desarrollo de los puentes y túnel en el desarrollo portuario. Es decir, la pregunta que nos formularemos es si la creación de las grandes obras de infraestructura que conectaron a Entre Ríos con otros territorios fue la principal causa del decaimiento de la dinámica portuaria. Es un trabajo pionero en torno al análisis de los puertos fluviales del Litoral argentino ya que, si bien para las primeras décadas del siglo XX encontramos la obra de Ricardo Ortiz (1943) y trabajos recientes que sutilmente se aproximan a la problemática (Mateo, 2018; Mateo y Goularti Filho, 2017) no se encuentran investigaciones que den cuenta de esta problemática en concreto.

\section{La fuente}

La navegación fluvial fue languideciendo a medida que el camión fue reemplazando al resto de los sistemas de transporte. A ello contribuyó una serie de disposiciones impuestas a aquel sistema y que no afectaban al resto como ser sanitarias, aduaneras, policiales, consulares e impositivas, temporarias algunas y permanentes otras, pero todas la afectaron económicamente y produjeron demoras operativas (Ferreira, 1970, p. 285). En efecto, el hecho de que toda mercancía salida por los puertos deba ser registrado por alguna autoridad fiscal, lo cual es un elemento que restringe la operatividad del transporte fluvial contra otros sistemas de transporte, se convierte, sin embargo, en un aspecto de singular importancia para la recuperación de la información del contenido de a las operaciones de transporte fluvial. Ya sea que las mercancías hayan sido transportadas hacia otro puerto dentro del sistema aduanero nacional como destino final, o que fueran llevadas a otro puerto para hacer luego exportadas al exterior ("removido") o exportadas directamente, esto debe ser registrado por la aduana. Lo cual nos permite contar con una información detallada de todo aquello que salió por los puertos, que seguramente fue anotado en los libros aduaneros pero que han sido mayormente destruidos. No obstante, ha quedado registrado en los Anuarios de Comercio Exterior de la Argentina.

Alcanzar esta información no es sin embargo una tarea simple y directa, ya que según sea el período analizado de esta importantísima fuente, las mercancías son o anotadas directamente o codificadas con criterios diferentes. Hemos resumido la información según los criterios de la Nomenclatura de Exportación utilizada a partir de 1966 reemplazando a la que operaba desde 1958. En efecto, en el año 1965, durante la presidencia de Arturo Humberto Illia, la Secretaría de Estado de Hacienda de su gobierno adaptó los códigos de las mercancías del comercio exterior a las categorías y subcategorías de la Nomenclatura Arancelaria de Bruselas (Decreto de Ley 8999, 1965 y Ley 16.686, 1966). El mismo dividía a las mercancías en 21 secciones, cada una con sus capítulos, partidas, subpartidas e ítems, de tal forma de alcanzar un máximo nivel de desagregación de cada artículo. El ordenado parte de una producción primaria y 
Mateo, Camarda y Ranieri. Los puertos, las exportaciones y las conexiones materiales de Entre Ríos (1958-1983).

avanza hacia manufacturas con cada vez mayor grado de desagregación, finalizando en la última sección con obras de arte y colecciones.

A modo de ejemplo, un producto como la "harina de trigo" está registrada en la sección II ("Productos del reino vegetal”), en su capítulo 11 ("Productos de la molinería; malta; almidones y féculas; gluten; inulina"), en su partida 01 ("harina de cereales"), en la subpartida 01 ("De trigo o de comuña o morcajo") y finalmente en su ítem 01 ("harina de trigo"). Para este trabajo hemos optado por clasificar a las mercancías en secciones y capítulos para un análisis general procediendo en un desagregado más amplio en algunas de ellas por su peso en el volumen general o por su singularidad o destaque.

\section{Los puertos, terminales portuarias y conexiones de Entre Ríos}

Como hemos dicho, trece terminales portuarias tuvieron actividad aduanera durante el período analizado. Como podemos ver en el Mapa 1, en el Río Paraná en el extremo norte se ubica el puerto de La Paz, que probablemente extendía su hinterland al sur de la vecina provincia de Corrientes. Unos pocos kilómetros al sur se encuentra el puerto de Santa Elena, íntimamente vinculado al trabajo realizado en su frigorífico. En el distrito de Paraná se encontraban en actividad dos puertos: Hernandarias, casi en el punto que deslinda los partidos de La Paz y Paraná y el de la capital de la provincia, cercano al Túnel Subfluvial. Al sur de este el importante puerto de Diamante, en la ciudad cabecera de este distrito. Más al sur la localidad de Victoria también sumaba actividad aduanera entre afluentes y bañados que tenían como destino final al puerto de Rosario. Con características similares, entre meandros la localidad de Gualeguay sumaba un punto más de extracción. El río Paraná ofrecía un último puerto frente a las márgenes de Zárate, en la provincia de Buenos Aires: Ibicuy, un puerto con fuerte potencial pero muy cercano al complejo Zárate-Brazo largo.

De norte a sur, también, la margen del Uruguay ofrecía otras cinco terminales portuarias. Dos en el departamento de Concordia (el homónimo y el cercano a éste de Yuquerí), con algunas dificultades de navegación aguas abajo. El de Colón, que en realidad contenía dos terminales ya que sumaba al de la fábrica Liebig unos kilómetros al norte de éste vinculado a otro frigorífico especializado durante décadas en la producción de corned beef. Pocos kilómetros al sur tenemos al puerto de Concepción del Uruguay y finaliza este frente fluvial con el puerto de Gualeguaychú también vinculado a la actividad frigorífica. Salvo el de Concepción del Uruguay todos los puertos del Uruguay están ubicados anejos a obras de vinculación con la República Oriental del Uruguay. Otras terminales portuarias como Curtiembre, Pueblo Brugo o Federación que habían registrado actividad años antes (Mateo, 2018) no la tuvieron en el período que analizamos.

Sintetizamos como fue la vinculación de Entre Ríos previo a la conexión material. Desde la ocupación humana de la mesopotamia argentina el río fue cruzado a través de balsas y canoas e incluso a lomo de caballo. El 29 de mayo de 1908, luego de idas y venidas y de instalaciones en lugares anegadizos en temporadas de lluvias, se inauguró el primer ferry boat sobre el cual se montaban locomotoras y vagones de ferrocarril. 
Conectaba Zárate con Ibicuy y para su inauguración se encontraba el presidente de la Nación Dr. Figueroa Alcorta, el Ministro de Obras Públicas Dr. Ezequiel Ramos Mejía, los Ministros de Hacienda, Agricultura y Guerra, el Gobernador de la Provincia de Buenos Aires Ignacio Irigoyen, el Intendente de Bs. As. Manuel Güiraldes, ministros de Inglaterra, Francia entre otras personalidades de renombre. A este primogénito ferry le sumaron dos nuevos navíos y recién entre 1926 y 1929 tres barcos más, estos últimos unían Ibicuy con la desembocadura del Riachuelo en Buenos Aires.

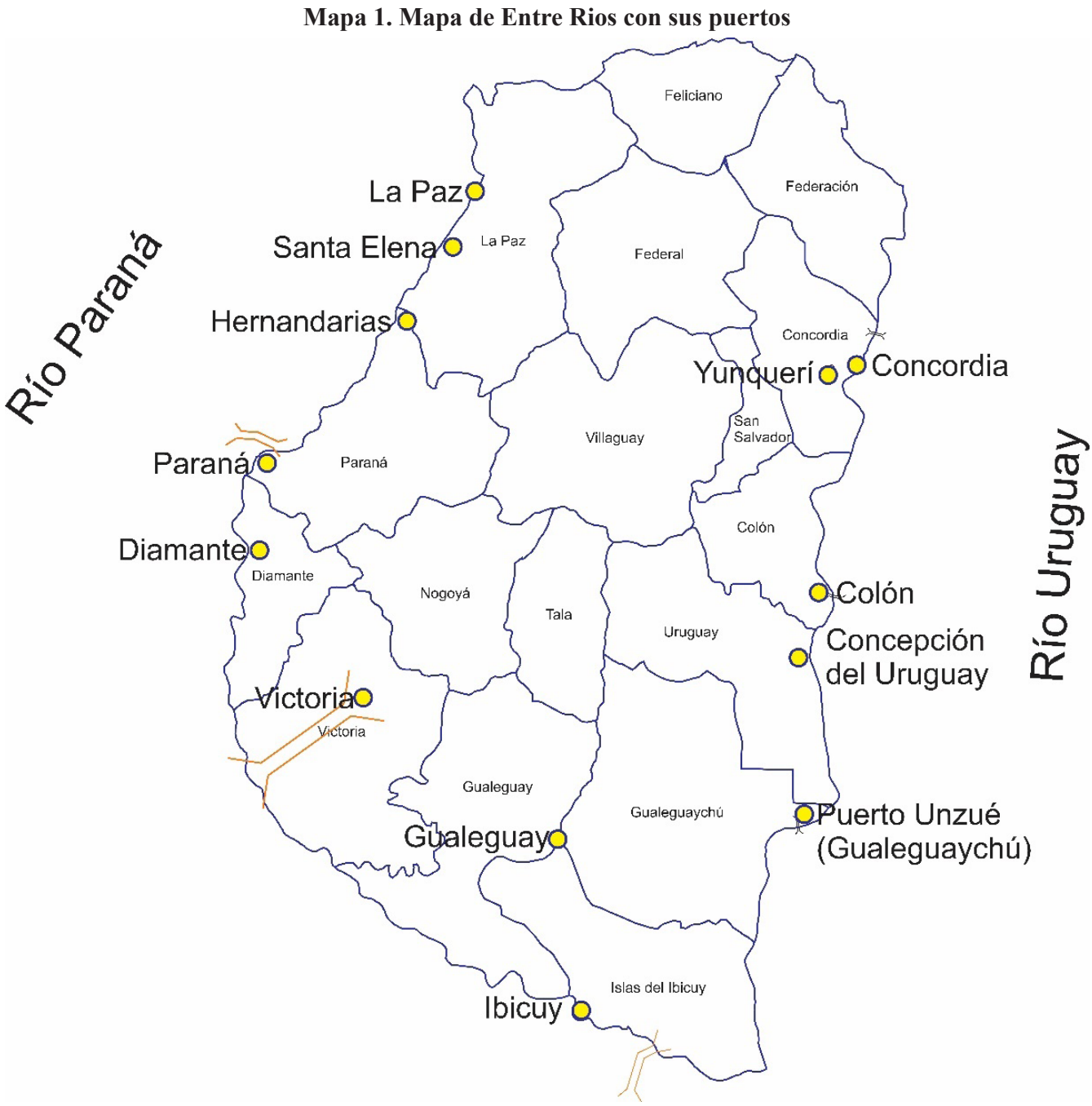

Hacia fines de la década de 1920 se comenzó la construcción de balsas para el transporte de vehículos realizando el trayecto Paraná-Santa Fe, para ello se construyeron además embarcaderos para ese fin en las dos márgenes del río. Este servicio se inauguró el 27 de febrero de 1929. Se realizaban dos viajes diarios y se transportaba un máximo 
Mateo, Camarda y Ranieri. Los puertos, las exportaciones y las conexiones materiales de Entre Ríos (1958-1983).

de 400 personas y 100 vehículos por día. Para el año 1931 se encontraban dos balsas en servicio realizando 8 viajes diarios y 3267 viajes en el año. El impacto de este servicio fue muy importante ya que se transportaron más de 15.000 automóviles, de 20.000 camiones y 210.000 pasajeros, logrando el Ministerio de Obras Públicas (que gestionaba el transporte) una recaudación de más de 330.000 pesos. Este sistema de balsas fue el que perduró durante las décadas siguientes hasta que su utilización fue puesta en tensión a partir del incremento de la densidad del tráfico.

Si bien desde principios del siglo XX se desarrollaron intentos de proyecto vinculados a la conexión por puente o túnel de Entre Ríos con el resto de los territorios, lo cierto es que a partir de mediados de siglo comenzaron a tomar forma proyectos ejecutables en torno a ello. En el cuadro siguiente podemos observar las fechas de inicio y finalización de las grandes obras de infraestructura que conectó a Entre Ríos.

Tabla 1. Obras de conexión de Entre Rios entre 1969 a 1979

\begin{tabular}{lllll}
\hline Obra & Tipo & Inicio & Inaugurado & Tipo \\
\hline $\begin{array}{l}\text { Túnel subfluvial } \\
\text { Hernandarias }\end{array}$ & Túnel carretero & 1962 & 1969 & $\begin{array}{l}\text { Nacional (Santa Fe- } \\
\text { Entre Ríos) }\end{array}$ \\
\hline $\begin{array}{l}\text { Puente Colón- } \\
\text { Paysandú }\end{array}$ & Puente carretero & 1973 & 1975 & $\begin{array}{l}\text { Binacional (Argentina- } \\
\text { Uruguay) }\end{array}$ \\
\hline $\begin{array}{l}\text { Puente Puerto Unzué- } \\
\text { Fray Bentos }\end{array}$ & Puente carretero & 1972 & 1976 & $\begin{array}{l}\text { Binacional (Argentina- } \\
\text { Uruguay) }\end{array}$ \\
\hline $\begin{array}{l}\text { Complejo Zárate- } \\
\text { Brazo Largo }\end{array}$ & $\begin{array}{l}\text { Puente } \\
\text { ferroautomotor }\end{array}$ & 1972 & 1977 & $\begin{array}{l}\text { Nacional (Buenos } \\
\text { Aires-Entre Ríos) }\end{array}$ \\
\hline $\begin{array}{l}\text { Complejo Salto- } \\
\text { Grande }\end{array}$ & $\begin{array}{l}\text { Central } \\
\text { hidroeléctrica y paso } \\
\text { ferroautomotor }\end{array}$ & 1974 & 1979 & $\begin{array}{l}\text { Binacional (Argentina- } \\
\text { Uruguay) }\end{array}$ \\
\hline
\end{tabular}

La conexión de Entre Ríos se produjo a partir de la inauguración del túnel subfluvial en 1969 y en los siguientes 10 años se inauguraron cuatro obras de conexión más. Esto aceleró el proceso de comunicación de transporte por camión, el cual anteriormente cruzaba los ríos con el sistema de balsas. Ahora, profundizaremos el análisis en torno a si se observan modificaciones de la dinámica de las Aduanas portuarias con la habilitación de estas conexiones.

La participación de las aduanas portuarias de Entre Ríos durante el período estudiado promedió el 0,45\% del total de los valores FOB (free on board) declarados en las aduanas del país. Como puede verse en el Gráfico 1, las oscilaciones fueron fuertes, duplicando ese valor en 1958, 1971 (año de mayor participación del período) y 1981. El puerto de Colón y su cercano Yuquerí fueron los responsables del comportamiento de 1958 y en los dos otros casos lo fue el puerto de Diamante. Los tres momentos en que la línea de flotación del 0,4\% fue más fuertemente afectada fue entre los años 1959 y 1964 y entre 1968 y 1973. Salvo el último, los tres primeros momentos fueron anteriores a la inauguración del túnel subfluvial. 
Gráfico 1. Participación porcenbtual de las aduanas de Entre Ríos en función de los valores FOB declarados en las aduanas argentinas (eje principal) y valores declarados en USD (eje secundario) en el período 1958-1983

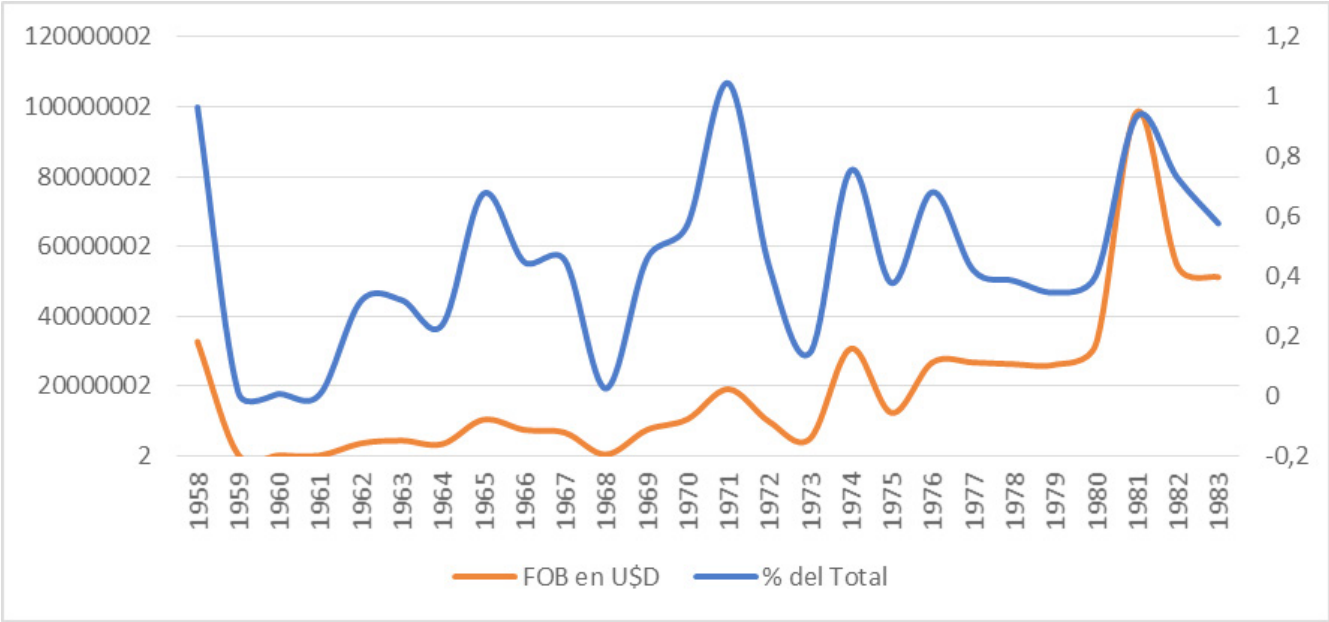

Fuente: Anuarios de Comercio Exterior (1958-1983)

Gráfico 2. Actividad de los puertos de Entre Ríos en el período 1958-1983

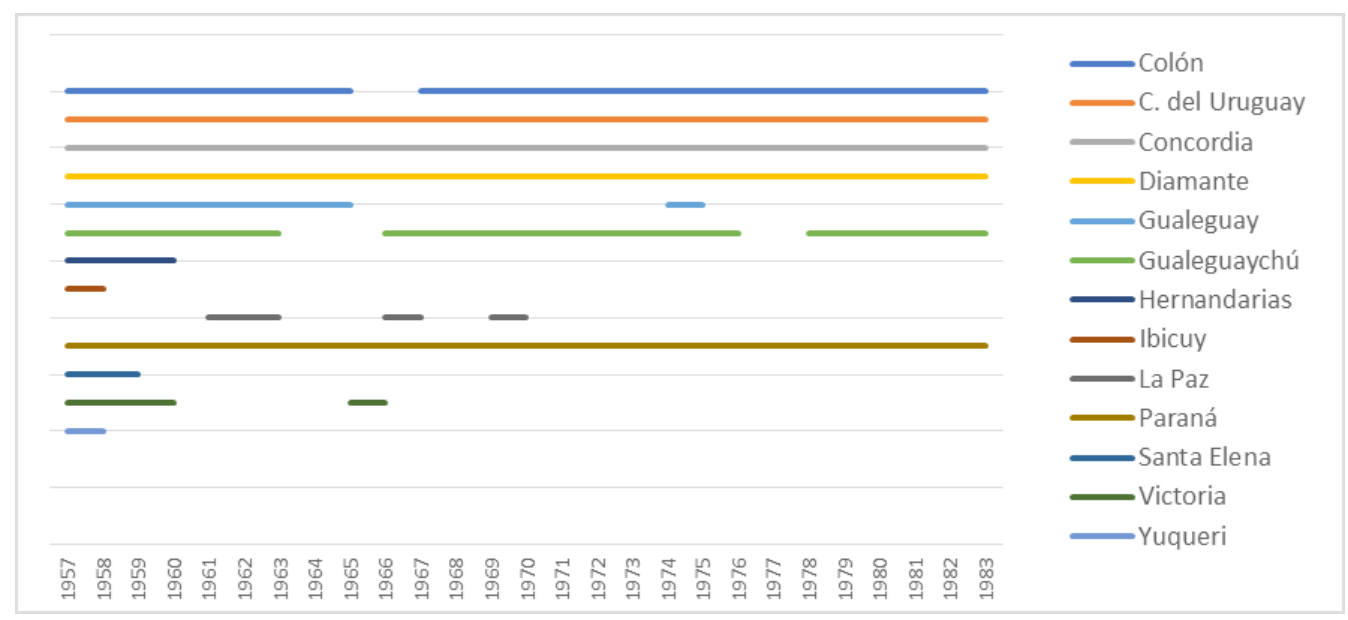

Fuente: Anuarios de Comercio Exterior (1958-1983)

Los valores FOB en dólares son coherentes con esta distribución, tanto en sus más como en sus menos. Es natural, ya que se trata de la misma fuente, pero al menos sirve de control de errores en la carga de los datos. Un segundo elemento que considerar es la continuidad o la presencia episódica de los puertos entrerrianos en la actividad exportadora. Los trece puertos de Entre Ríos activos a partir de la información de sus aduanas, receptoría y resguardos, durante este período muestran, algunos, una fuerte continuidad (Colón, Paraná, Concepción del Uruguay y Diamante) y otros que aparecen 
Mateo, Camarda y Ranieri. Los puertos, las exportaciones y las conexiones materiales de Entre Ríos (1958-1983).

y desaparecen episódicamente (Hernandarias, Ibicuy, Santa Elena, Victoria y Yuquerí) y vemos un tercer tipo, Gualeguay, que reparte casi en mitades una fuerte actividad aduanera con tres años de inactividad.

En el Gráfico 2 hemos querido ilustrar este comportamiento, señalando en colores los años de actividad de los puertos y dejando en blanco los de falta de ella. Como se podrá observar, los puertos de Ibicuy, Santa Elena y Yuquerí tuvieron solo un año de actividad registrada (1958), La Paz tuvo participación alternada, Gualeguay no llega a la mitad de los años, Victoria a seis y Hernandarias a 4. El período finaliza con los puertos de La Paz, Gualeguay, Hernandarias, Ibicuy - uno de los puertos clave de Entre Ríos en la actualidad-, Santa Elena, Victoria y Yuquerí sin actividad.

\section{Las mercancías salidas por los puertos}

La primera pregunta que nos hacemos ahora es: ¿cuál fue la participación de estos puertos en los valores aduaneros provinciales declarados durante el período?

Gráfico 3. Participación de cada puerto entrerriano en valorees FOB en U\$D en el período 1958-1983

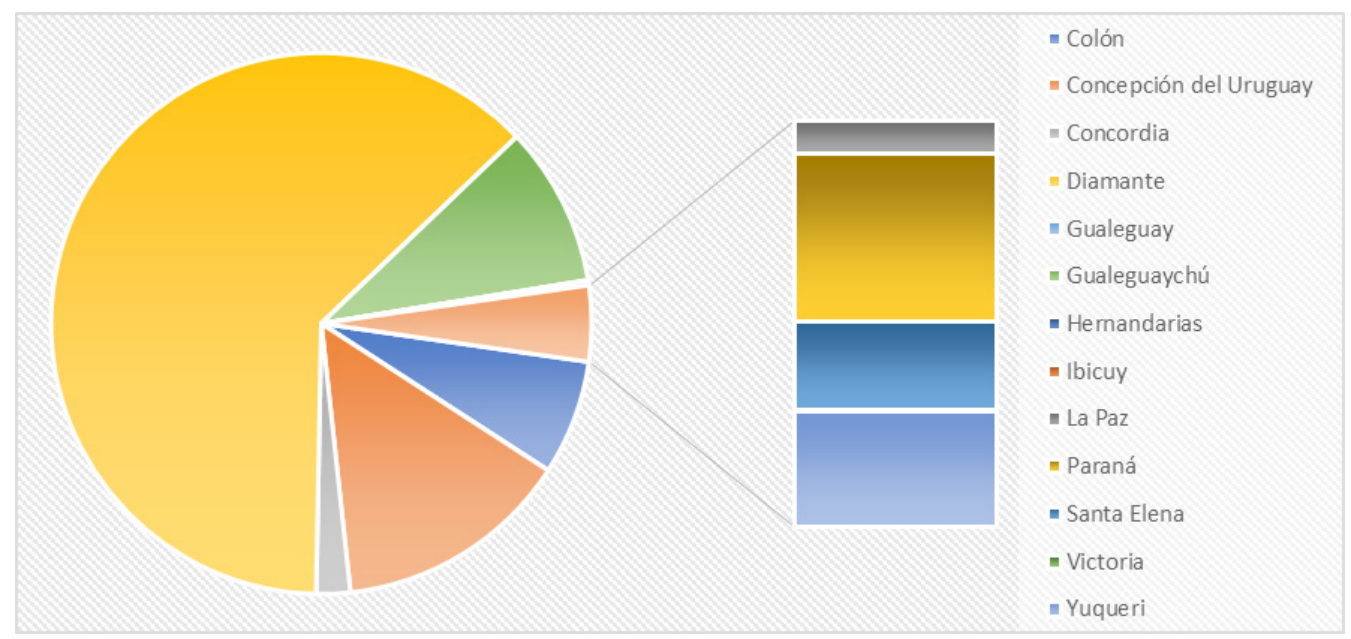

Fuente: Anuarios de Comercio Exterior (1958-1983)

Con los datos de la del Apéndice 1 (Gráfico 3) podemos establecer ese ranking y afirmar que el puerto de Diamante, con un monto total de U\$D de 315.980.327, lo que equivalía al 63\% del total en el período (U\$D 505.109.165) fue el puerto hegemónico por su actividad, seguido muy de atrás del de Concepción del Uruguay con el $14 \%$ (U\$D 71.431.474) y Gualeguaychú con el 10\% de la declaración del valor FOB en la moneda estadounidense (U\$D 48.324.230). Estos tres puertos concentraron el 87\% de los valores FOB, dejando apenas un 13\% para el resto de las terminales de la provincia.

La centralidad del puerto de Diamante, la encontramos vinculada a la existencia de un círculo virtuoso que conecta la producción del Departamento de Paraná cuya 
concentración se ubicaba en Crespo y su salida por el puerto de Diamante. Esta dinámica fue posible por la existencia durante este periodo de las rutas 11, 12 y 131 que arma un triángulo en la conectabilidad de estos territorios.

Desagregados por años (Gráfico 4), vemos que desde 1962 la posición de Diamante fue dominante y desde 1969 a 1977 hegemónica, posición que vuelve a obtener hacia final del período. Concordia, entre 1959 y 1961 tuvo su momento de esplendor, pero probablemente las dificultades de la navegación hacia el sur del Río Uruguay (por los "Saltos Grandes" y "El hervidero") lo fueron desplazando, sobre todo al no construirse la esclusa y canal de navegación proyectados y nunca construidos en la represa de Salto Grande. A pesar de esto vemos una nueva aparición importante de Concordia entre 1977 y 1978 exportando manufacturas de origen industrial (MOI).

Gráfico 4. Evolución de los puertos entrerriano en (valores FOB en U\$D) en el período 1958-1983

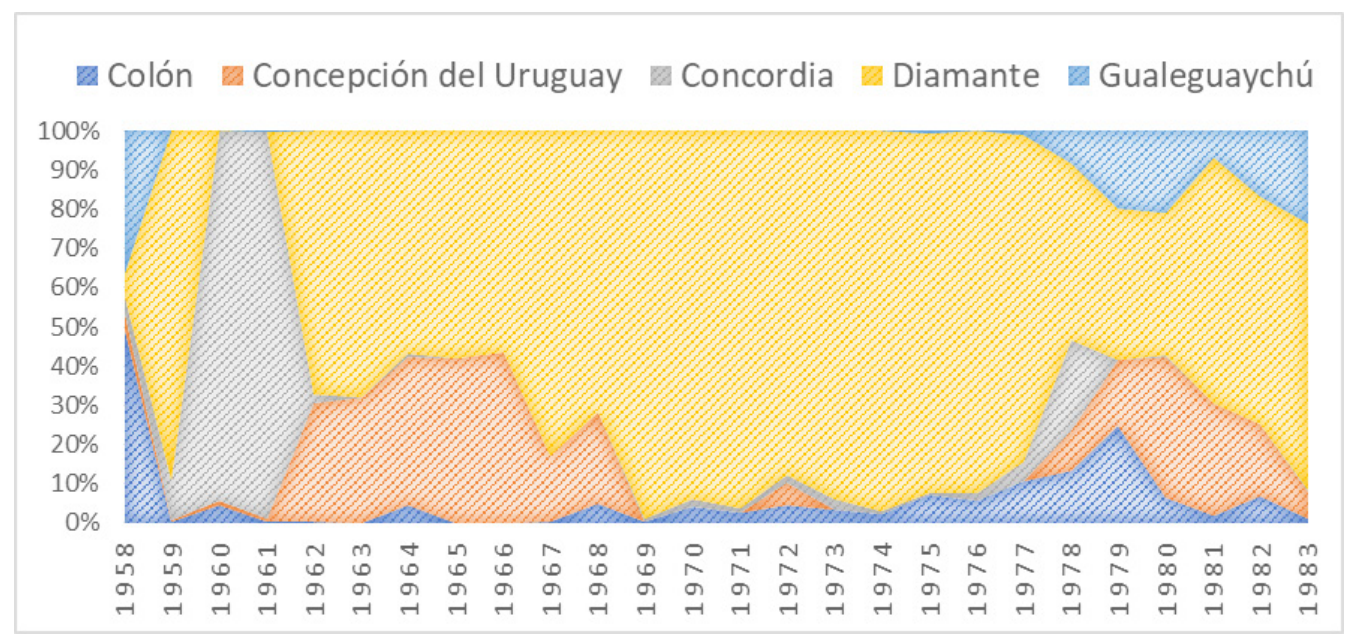

Fuente: Anuarios de Comercio Exterior (1958-1983)

Entre 1975 y 1979 el puerto de Colón se sumó al liderazgo episódicamente con producción similar a la de Concordia y pieles y cueros. Una segunda pregunta, que surge de este acápite es ¿qué mercancías salían por esos puertos? En la Tabla 2 se desagregan 20 de las 21 categorías de la Nomenclatura Arancelaria de Bruselas presentes en el registro y podemos hacer un primer balance. Como es de suponer se destacan los derivados agropecuarios, siendo los "productos del reino vegetal" los que concentran casi el $74 \%$ de estas exportaciones, seguido con un $9 \%$ por los "animales vivos" y otros "productos del reino animal". 


\section{ARTÍ́CULOS}

Mateo, Camarda y Ranieri. Los puertos, las exportaciones y las conexiones materiales de Entre Ríos (1958-1983).

Tabla 2. Valor FOB en USD de las exportaciones de Entre Ríos según la nomenclatura de Bruselas (1958-1983)

\begin{tabular}{|c|c|c|c|}
\hline Contenido sección & $\begin{array}{l}\text { Valores FOB } \\
(\mathbf{u} \$ d)\end{array}$ & $\begin{array}{c}\overline{\mathrm{x}} \\
\text { anual }\end{array}$ & $\%$ (u\$d) \\
\hline Animales vivos y productos del reino animal & 44457897 & 1709919,1 & $8,80 \%$ \\
\hline Armas y municiones & 894998 & 34423,0 & $0,18 \%$ \\
\hline $\begin{array}{l}\text { Calzados; sombrerería; paraguas y quitasoles; flores } \\
\text { artificiales y manufacturas de cabellos; abanicos }\end{array}$ & 40241 & 1547,7 & $0,01 \%$ \\
\hline Encomiendas & 74196 & 2853,7 & $0,01 \%$ \\
\hline $\begin{array}{c}\text { Grasas y aceites (animales y vegetales); productos de su } \\
\text { desdoblamiento; grasas alimenticias elaboradas; ceras de } \\
\text { origen animal o vegetal }\end{array}$ & 22924375 & 881706,7 & $4,54 \%$ \\
\hline $\begin{array}{l}\text { Instrumentos y aparatos de óptica, de fotografía y de } \\
\text { cinematografía, de medida, de comprobación, de precisión; } \\
\text { instrumentos y aparatos médico-quirúrgicos; relojería; } \\
\text { instrumentos de música; aparatos para el registro y } \\
\text { reproducción del sonido o para el registro y reproducción } \\
\text { en televisión por procedimiento magnético; de imágenes y } \\
\text { sonido }\end{array}$ & 18927 & 728,0 & $0,00 \%$ \\
\hline $\begin{array}{c}\text { Madera, carbón vegetal y manufacturas de madera; corcho y } \\
\text { sus manufacturas; manufacturas de espartería y cestería }\end{array}$ & 703336 & 27051,4 & $0,14 \%$ \\
\hline $\begin{array}{c}\text { Manufacturas de piedra, yeso, cementos, aislante, mica } \\
\text { y materias análogas; productos cerámicos; vidrio y } \\
\text { manufacturas de vidrio }\end{array}$ & 197358 & 7590,7 & $0,04 \%$ \\
\hline Máquinas y aparatos; material eléctrico & 709695 & 27296,0 & $0,14 \%$ \\
\hline Material de transporte & 2142588 & 82407,2 & $0,42 \%$ \\
\hline $\begin{array}{l}\text { Materias plásticas artificiales, éteres y ésteres de la celulosa, } \\
\text { resinas artificiales y manufacturas de estas materias, caucho } \\
\text { natural o sintético, caucho facticio y manufacturas de caucho }\end{array}$ & 696778 & 26799,2 & $0,14 \%$ \\
\hline Materias textiles y sus manufacturas & 674304 & 25934,8 & $0,13 \%$ \\
\hline $\begin{array}{l}\text { Materias utilizadas en la fabricación del papel; papel y sus } \\
\text { aplicaciones }\end{array}$ & 1135513 & 43673,6 & $0,22 \%$ \\
\hline $\begin{array}{l}\text { Mercancías y productos varios, no expresados ni } \\
\text { comprendidos en otra parte }\end{array}$ & 34391 & 1322,7 & $0,01 \%$ \\
\hline Metales comunes y manufacturas de estos metales & 6686958 & 257190,7 & $1,32 \%$ \\
\hline $\begin{array}{l}\text { Perlas finas, piedras preciosas y semipreciosas y similares, } \\
\text { metales preciosos, chapados de metales preciosos y } \\
\text { manufacturas de estas materias; bisutería de fantasía; monedas }\end{array}$ & 11099771 & 426914,3 & $2,20 \%$ \\
\hline $\begin{array}{c}\text { Pieles, cueros, peletería y manufacturas de estas materias; } \\
\text { artículos de guarnicionería, talabartería y viaje; marroquinería } \\
\text { y estuchería; tripas manufacturadas }\end{array}$ & 6868159 & 264160,0 & $1,36 \%$ \\
\hline $\begin{array}{l}\text { Productos de las industrias alimenticias; bebidas; líquidos } \\
\text { alcohólicos y vinagre y tabaco }\end{array}$ & 21403963 & 823229,3 & $4,24 \%$ \\
\hline $\begin{array}{l}\text { Productos de las industrias químicas y de las industrias } \\
\text { conexas }\end{array}$ & 8136519 & 312943,0 & $1,61 \%$ \\
\hline Productos del reino vegetal & 373059539 & 14348443,8 & $73,86 \%$ \\
\hline Productos minerales & 3149659 & 121140,7 & $0,62 \%$ \\
\hline Total general & 505109165 & & $100,00 \%$ \\
\hline
\end{tabular}

Fuente: Anuarios estadísticos de comercio exterior de la República Argentina 
Sin embargo, la diversidad de productos salidos por este medio es inmensa y nos habla de una capacidad manufacturera muy poco reconocida para la provincia. En efecto, desde "armas y municiones" hasta productos químicos, pasando por calzados e instrumentos de precisión, las manufacturas de origen industrial exportaron en conjunto por valores por encima de la ganadería. Por su parte las manufacturas producto de la agroindustria suman en conjunto un valor superior en este caso al 6\%. Completan el cuadro productos no incluidos en la Nomenclatura (ni en el registro), las encomiendas que no determinan su contenido y los muestrarios no llegando en conjunto al $1 \%$ de lo salido.

Vayamos ahora a analizar las exportaciones principales. Comencemos por los cereales.

Tabla 3. Cereales salidos por los puertos de Entre Ríos entre 1958 y 1983 (en kilogramos)

\begin{tabular}{|c|c|c|c|c|c|c|c|c|}
\hline Puertos & Arroz & Avena & Cebada & Lino & Maíz & Otros & Trigo & Total \\
\hline Colón & & 106780 & 2177 & & 50669 & 367430 & 5673250 & 6200306 \\
\hline $\begin{array}{l}\text { Concepción } \\
\text { del Uruguay }\end{array}$ & 152129381 & & & & & & 78519350 & 230648731 \\
\hline Concordia & 393268 & & & & & & & 393268 \\
\hline Diamante & 9379010 & & & 458 & 1064728457 & 1572462208 & 184078342 & 2830648475 \\
\hline Gualeguaychú & & 1730020 & 30000 & & 3624049 & 897200 & 5791868 & 12073137 \\
\hline Hernandarias & & & & & & & 1850000 & 1850000 \\
\hline $\mathrm{La} \mathrm{Paz}$ & & & & & 895 & & 7485487 & 7486382 \\
\hline Paraná & & & & & & & 2506070 & 2506070 \\
\hline Total & 161901659 & 1836800 & 32177 & 458 & 1068404070 & 1573726838 & 285904367 & 3091806369 \\
\hline$\%$ & 5,2 & 0,1 & 0,0 & 0,0 & 34,6 & 50,9 & 9,2 & 100,0 \\
\hline
\end{tabular}

Fuente: Anuarios estadísticos de comercio exterior de la República Argentina

En la Tabla 2 podemos observar cómo la clasificación "otros cereales" con casi el $51 \%$ del total de cereales exportados, y el puerto de Diamante con casi el $92 \%$ de la exportación cerealera, dominan el conjunto. Más adelante develaremos de qué se tratan estos "otros cereales". Previamente, presentamos un resumen porcentual de la Tabla 3 , donde puede observarse que Concepción del Uruguay y su vecino el de Concordia fueron puertos esencialmente arroceros. El de Diamante diversificado entre maíz, trigo y "otros cereales", al igual que Gualeguaychú que diversificaba en exportaciones de trigo, maíz, avena y una pequeña proporción de "otros". Los puertos no señalados no generaron exportaciones de estos cereales. 
Mateo, Camarda y Ranieri. Los puertos, las exportaciones y las conexiones materiales de Entre Ríos (1958-1983).

Tabla 4. Desagregados por tipo de cereal salidos por los puertos de Entre Ríos entre 1958 y 1983 (en kilogramos)

\begin{tabular}{cccccccc}
\hline Puertos & Arroz & Avena & Cebada & Lino & Maíz & Otros cereales & Trigo \\
\hline Colón & 0,0 & 1,7 & 0,0 & 0,0 & 0,8 & 5,9 & 91,5 \\
\hline Concepción del Uruguay & 66,0 & 0,0 & 0,0 & 0,0 & 0,0 & 0,0 & 34,0 \\
\hline Concordia & 100,0 & 0,0 & 0,0 & 0,0 & 0,0 & 0,0 & 0,0 \\
\hline Diamante & 0,3 & 0,0 & 0,0 & 0,0 & 37,6 & 55,6 & 6,5 \\
\hline Gualeguaychú & 0,0 & 14,3 & 0,2 & 0,0 & 30,0 & 7,4 & 48,0 \\
\hline
\end{tabular}

Fuente: Anuarios estadísticos de comercio exterior de la República Argentina exportaciones?

¿Cuáles eran esos "otros cereales" que constituían más de la mitad de las

Tabla 5. Desagregación de los cereales con menor representatividad salidos por los puertos de Entre Ríos entre 1958 y 1983 (en kilogramos)

\begin{tabular}{cccccc}
\hline Puerto & Alpiste & Mijo & Otros & Sorgo & Total \\
\hline Colón & 237430 & & & 130000 & 367430 \\
\hline Diamante & & 11871000 & & 1560591208 & 1572462208 \\
\hline Gualeguaychú & & & 19920 & 877280 & 897200 \\
\hline Total & $\mathbf{2 3 7 4 3 0}$ & $\mathbf{1 1 8 7 1 0 0 0}$ & $\mathbf{1 9 9 2 0}$ & $\mathbf{1 5 6 1 5 9 8 4 8 8}$ & $\mathbf{1 5 7 3 7 2 6 8 3 8}$ \\
\hline
\end{tabular}

Fuente: Anuarios estadísticos de comercio exterior de la República Argentina

La Tabla 5 es clara, se trataba del sorgo, un cereal utilizado para diversas producciones y usos como consumo humano, animal, en la producción de forrajes, $y$ para la elaboración de bebidas alcohólicas e incluso escobas. Su resistencia a la sequía y el calor lo hace un cultivo importante en regiones áridas, y es uno de los cultivos alimentarios más importantes del mundo. ${ }^{1}$ Este cereal produjo el ingreso de más del 30\% de las exportaciones fluviales de la provincia en el período estudiado (USD 152.415.080 sobre los U\$D 505.109.165 del total.

Pasemos ahora a las exportaciones "del mundo animal” según la nomenclatura de Bruselas (tabla 5). Tres productos lideran este rubro. El mayoritario es la agroindustria de la carne (enfriada o congelada) con un $45 \%$ del total, seguida de los porcinos en pie $(21,5 \%)$ y derivados como la leche, los huevos y la miel. Se sumaron las aves de corral vivas con cerca de un $9 \%$

1 El sorgo junto al trigo en Europa, el arroz en Asia y al maíz en América se lo cuenta entre los cuatro cereales que permitieron la conocida "revolución agrícola" en la historia de la humanidad (Fontana, 1997). 
Tabla 6. Productos ganaderos salidos por los puertos de Entre Ríos entre 1958 y 1983

\begin{tabular}{ccc}
\hline Producto & U\$D & $\%$ \\
\hline Porcinos & 9576597 & 21,5 \\
\hline Aves de corral & 3895712 & 8,8 \\
\hline Carne fresca & 19844517 & 44,6 \\
\hline Otros animales vivos & 6580 & 0,0 \\
\hline Bovinos & 414681 & 0,9 \\
\hline Caballos & 97691 & 0,2 \\
\hline Leche, huevos y miel & 9806543 & 22,1 \\
\hline Cerdas equinas y bovinas & 14774 & 0,0 \\
\hline Carnes y menudencias curadas o saladas & 699101 & 1,6 \\
\hline Ovinos & 90501 & 0,2 \\
\hline Total & 44446697 & 100,0 \\
\hline
\end{tabular}

Fuente: Anuarios estadísticos de comercio exterior de la República Argentina

En conjunto estos cuatro productos concentran el $97 \%$ de las de derivados agropecuarios. La distribución por puertos muestra lo que se podía suponer: aquellos ligados a la industria frigorífica son los que también se destacan en las exportaciones de carne enfriada o congelada: Gualeguaychú el 34,4\%, Yuquerí (Benito Legerén o Frigorífico Yuquerí o CAP, Corporación Argentina de Productores, de carne), el 25,6\%, Santa Elena, el 16,1\% y Colón, el 14,5\% suman el 90,6\% de la exportación de este producto.

Tabla 7. Distribución de los productos ganaderos salidos por los puertos de Entre Ríos entre 1958 y 1983

\begin{tabular}{|c|c|c|c|c|c|c|c|c|c|c|c|}
\hline Puertos & Porcinos & $\begin{array}{l}\text { Aves de } \\
\text { corral }\end{array}$ & $\begin{array}{c}\text { Carne } \\
\text { fresca } \\
\text { (enfriada o } \\
\text { congelada) } \\
\end{array}$ & $\begin{array}{c}\text { Otros } \\
\text { animales } \\
\text { vivos }\end{array}$ & Bovinos & Caballos & $\begin{array}{l}\text { Leche, } \\
\text { huevos } \\
\text { y miel }\end{array}$ & $\begin{array}{c}\text { Cerdas } \\
\text { equinas } \\
y \\
\text { bovinas } \\
\end{array}$ & $\begin{array}{c}\text { Carnes y } \\
\text { menudencias } \\
\text { curadas o } \\
\text { saladas } \\
\end{array}$ & Ovinos & Total \\
\hline Colón & 6561194 & 174488 & 2871210 & 6280 & 263252 & 3741 & 24800 & 2774 & & & 9907739 \\
\hline $\begin{array}{l}\text { Concepción } \\
\text { del Uruguay }\end{array}$ & & & 12231 & & & 545 & 634310 & & & 76380 & 723466 \\
\hline Concordia & & & 188325 & 300 & 37988 & 11874 & 68926 & & 419663 & 12041 & 739117 \\
\hline Diamante & & & 1242504 & & & & 417534 & & & & 1660038 \\
\hline Gualeguaychú & 2986584 & 2643451 & 6818074 & & 62843 & 44220 & 33871 & 12000 & 6844 & 2080 & 12609967 \\
\hline $\mathrm{LaPaz}$ & & & 390369 & & & & & & & & 390369 \\
\hline Paraná & & & 32157 & & & & 8430661 & & & & 8462818 \\
\hline Santa Elena & & 15008 & 3201091 & & 50598 & 37311 & 136615 & & 27163 & & 3467786 \\
\hline Victoria & & & & & & & 59826 & & & & 59826 \\
\hline Yuquerí & 28819 & 1062765 & 5088556 & & & & & & 245431 & & 6425571 \\
\hline Total & 9576597 & 3895712 & 19844517 & 6580 & 414681 & 97691 & 9806543 & 14774 & 699101 & 90501 & 44446697 \\
\hline
\end{tabular}

Fuente: Anuarios estadísticos de comercio exterior de la República Argentina 


\section{ARTÍCULOS}

Mateo, Camarda y Ranieri. Los puertos, las exportaciones y las conexiones materiales de Entre Ríos (1958-1983).

Con existencia de frigoríficos menores y con un 6,3\% Diamante sumó un rubro más a su hegemonía como puerto. Haciendo una distribución de lo planteado, ahora en valores relativos, (Tabla 7) podemos acercarnos a las demás especializaciones portuarias de este rubro. La exportación de porcinos vivos la lideraba Colón, la de aves de corral vivas, caballos en pie, cerdas (equinas y bovinas) Gualeguaychú (al igual de la de carne fresca de todas las especies animales como vimos). Colón lidera también la de otros animales vivos, en general animales exportados para zoológicos como yacarés, pumas, ofidios, etc. y también la de bovinos en pie. La capital de la provincia y su puerto lideran un solo rubro, aunque ampliamente. Se trata de la agroindustria de la leche y los derivados agrarios de huevos y miel. Finalmente, el puerto de Concordia lideró la exportación de carnes y menudencias conservadas mediante el curado y el salado. Cabe aquí una aclaración: no estamos en ninguno de los casos determinando las especializaciones productivas de sus hinterlands, sino haciendo alusión solo a aquellas mercancías que tomaron la opción de salida de la provincia mediante sus puertos.

Tabla 8. Porcentajes de los productos ganaderos salidos por los puertos de Entre Ríos entre 1958 y 1983

\begin{tabular}{|c|c|c|c|c|c|c|c|c|c|c|c|}
\hline 竞 & $\begin{array}{l}0 \\
\stackrel{0}{0} \\
0 \\
0 \\
0\end{array}$ & 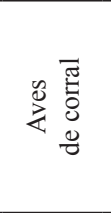 & 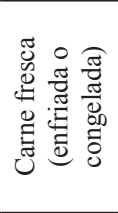 & 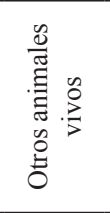 & 苂 & 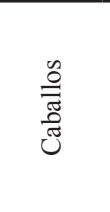 & 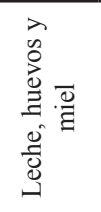 & 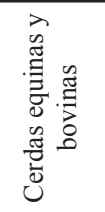 & 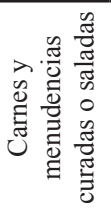 & 茴 & 莺 \\
\hline Gualeguaychú & $31,19 \%$ & $67,86 \%$ & $34,36 \%$ & $0,00 \%$ & $15,15 \%$ & $45,27 \%$ & $0,35 \%$ & $81,22 \%$ & $0,98 \%$ & $2,30 \%$ & $28,37 \%$ \\
\hline Colón & $68,51 \%$ & $4,48 \%$ & $14,47 \%$ & $95,44 \%$ & $63,48 \%$ & $3,83 \%$ & $0,25 \%$ & $18,78 \%$ & $0,00 \%$ & $0,00 \%$ & $22,29 \%$ \\
\hline Paraná & $0,00 \%$ & $0,00 \%$ & $0,16 \%$ & $0,00 \%$ & $0,00 \%$ & $0,00 \%$ & $85,97 \%$ & $0,00 \%$ & $0,00 \%$ & $0,00 \%$ & $19,04 \%$ \\
\hline Yuquerí & $0,30 \%$ & $27,28 \%$ & $25,64 \%$ & $0,00 \%$ & $0,00 \%$ & $0,00 \%$ & $0,00 \%$ & $0,00 \%$ & $35,11 \%$ & $0,00 \%$ & $14,46 \%$ \\
\hline Santa Elena & $0,00 \%$ & $0,39 \%$ & $16,13 \%$ & $0,00 \%$ & $12,20 \%$ & $38,19 \%$ & $1,39 \%$ & $0,00 \%$ & $3,89 \%$ & $0,00 \%$ & $7,80 \%$ \\
\hline Diamante & $0,00 \%$ & $0,00 \%$ & $6,26 \%$ & $0,00 \%$ & $0,00 \%$ & $0,00 \%$ & $4,26 \%$ & $0,00 \%$ & $0,00 \%$ & $0,00 \%$ & $3,73 \%$ \\
\hline Concordia & $0,00 \%$ & $0,00 \%$ & $0,95 \%$ & $4,56 \%$ & $9,16 \%$ & $12,15 \%$ & $0,70 \%$ & $0,00 \%$ & $60,03 \%$ & $13,30 \%$ & $1,66 \%$ \\
\hline $\begin{array}{c}\text { Concepción del } \\
\text { Uruguay } \\
\end{array}$ & $0,00 \%$ & $0,00 \%$ & $0,06 \%$ & $0,00 \%$ & $0,00 \%$ & $0,56 \%$ & $6,47 \%$ & $0,00 \%$ & $0,00 \%$ & $84,40 \%$ & $1,63 \%$ \\
\hline $\mathrm{La} \mathrm{Paz}$ & $0,00 \%$ & $0,00 \%$ & $1,97 \%$ & $0,00 \%$ & $0,00 \%$ & $0,00 \%$ & $0,00 \%$ & $0,00 \%$ & $0,00 \%$ & $0,00 \%$ & $0,88 \%$ \\
\hline Victoria & $0,00 \%$ & $0,00 \%$ & $0,00 \%$ & $0,00 \%$ & $0,00 \%$ & $0,00 \%$ & $0,61 \%$ & $0,00 \%$ & $0,00 \%$ & $0,00 \%$ & $0,13 \%$ \\
\hline Total & $100 \%$ & $100 \%$ & $100 \%$ & $100 \%$ & $100 \%$ & $100 \%$ & $100 \%$ & $100 \%$ & $100 \%$ & $100 \%$ & $100 \%$ \\
\hline
\end{tabular}

Fuente: Anuarios estadísticos de comercio exterior de la República Argentina

Finalmente, pasamos al análisis de la producción manufacturera, rubro que acompaña e incluso en conjunto supera al de productos y subproductos animales como hemos adelantado.

El desagregado es inmenso, hemos encontrado 161 rubros (Apéndice 2) que van desde productos químicos a aparatos de precisión, de bobinados de motores a calzado, 
de herrajes a juguetes, de muebles a "alambrón". ${ }^{2}$ Esto implicaba seguramente un ingreso de insumos importados significativos, y si bien en valores alcanza solo el 6,2\% del total es interesante destacar sus características regionales.

Lo primero que se destaca es que tres puertos y de la costa del Río Uruguay (Colón, Concordia y Gualeguaychú) concentraron más del 90\% de este tipo de exportaciones. Colón casi llegó al 40\% de total siendo los rubros principales el amoníaco, los aparatos y dispositivos para calentamiento, el armado de vehículos para transporte, el carbono, los chasis con motor, los explosivos y las máquinas agrícolas.

Tabla 9. Recaudación de los puertos de Entre Ríos entre 1958 y 1983

\begin{tabular}{ccc}
\hline Puerto & Recaudación USD & $\%$ de MOI \\
\hline Colón & 12193565 & $38,98 \%$ \\
\hline Concordia & 8066858 & $25,78 \%$ \\
\hline Gualeguaychú & 10991544 & $35,13 \%$ \\
\hline Resto & 33156 & $0,11 \%$ \\
\hline Total & 31285123 & $\mathbf{1 0 0 , 0 0 \%}$ \\
\hline
\end{tabular}

Fuente: Anuarios estadísticos de comercio exterior de la República Argentina

La concentración de la actividad manufacturera (Tabla 9) en estos puertos de la costra del Río Uruguay amerita una profundización en sus efectos económicos y sociales que excede los propósitos de este trabajo.

\section{Conclusiones}

Como se ha mostrado, recién al inicio del último tercio del siglo pasado la Mesopotamia argentina comenzó a conectarse por carretera con el resto del país. Sin embargo, los vagones de ferrocarril y los camiones cruzaban, aunque con dificultad, el Río Paraná con sus productos a bordo de embarcaciones desde muchas décadas antes de la inauguración del túnel subfluvial que une las ciudades de Paraná y Santa Fe. Entonces, la influencia directa de la puesta en funcionamiento del túnel, como de los otros puentes no fue un factor determinante en la dinámica portuaria. Los puertos, por lo tanto, antes o después del 13 de diciembre de 1969, cuando se abrió al tránsito el túnel, continuaron siendo una forma de extraer los excedentes productivos de la provincia. Durante el período estudiado, el registro aduanero de treces terminales portuarias (ocho sobre el Río Paraná y cinco sobre el Río Uruguay) confirman este juicio. Si bien todas las mercancías extraídas por medio fluvial eran pesadas, previo abordaje, el registro

\footnotetext{
2 El alambrón: es uno de los materiales más usados en las industrias. Dentro de sus aplicaciones se encuentran: maquinaria agrícola, automotrices, burlonería, electrodomésticos, etc. Sirve como materia prima de otros productos siderúrgicos como alambres crudos, recocidos, barras trefiladas, etc.
} 
Mateo, Camarda y Ranieri. Los puertos, las exportaciones y las conexiones materiales de Entre Ríos (1958-1983).

se llevó en diferentes unidades de medidas no convertibles (unidad, kilogramo, pies cúbicos, pares, etc.), lo cual, sin embargo, no reduce la calidad de la fuente.

Podemos afirmar, además, que solo seis de los trece puertos tuvieron una actividad constante durante el período: cuatro sobre el Río Uruguay (Colón, Gualeguaychú, Concepción del Uruguay y Concordia) y solo dos en la del Paraná (Paraná y Diamante). Sin embargo, fue el de Diamante el que hegemonizó según los procesos muy conocidos de evolución de las terminales costeras cercanas (Taaffe et al, 1963). Esta hegemonía creció notablemente como tal luego de la inauguración del túnel subfluvial. Los valores FOB de la provincia fueron muy inferiores a la de principios a mediados del siglo XX (Mateo y Camarda, 2018), pese a ello, estos fueron fluctuantes durante estos veintiséis años con doce durante el aislamiento y catorce con la conectividad plena.

Diamante, en efecto, fue el puerto más activo, y de los u\$d 505.109.165 de valores FOB declarados en estos años, este puerto movilizó u\$d 315.980.327. El rubro dominante fue el de los cereales y oleaginosas, con el trigo, el maíz y sobre todo el sorgo. A pesar de no contar la ciudad con frigoríficos importantes, en relación con los de Santa Elena, también en el caso de Gualeguaychú y Colón, la carne enfriada o congelada sumo una exportación considerable. Incluso, en este último caso, una carga importante de leche, huevos y miel.

Hasta aquí el trabajo complejiza lo conocido sobre la historia productiva de la provincia de Entre Ríos, desagregada en sus productos y regiones portuarias. Lo hace de una manera, hasta el momento no conocida, en cuanto al nivel de detalle en los estudios económicos de la provincia. Del análisis surge también una variada actividad de producción manufacturera, de muy diversa índole, que utilizaba también este medio de transporte que se ubicaba fuertemente sobre la rivera del Río Uruguay. En efecto, los puertos de Colón y Gualeguaychú, y un poco menos en el de Concordia, fueron utilizados para la extracción desde vehículos de carga y maquinaria agrícola (montada, reparada o revendida desde la provincia, no lo sabemos) hasta insumos para la fabricación de papel o balanzas de precisión con una variedad tipológica inmensa que compartían las bodegas de barcazas, chatas y otro tipo de embarcaciones. Este hecho amerita un estudio más en profundidad.

Intentamos medir y evaluar las mercancías registradas a la salida de los puertos (registro que también fue poco frecuente si el envío es por ferrocarril y casi inexistente si es por camión) y no de la producción de los hinterlands portuarios. Sin embargo, el trabajo responde algunas preguntas como el cuándo, cuánto, cómo y qué era extraído del excedente productivo provincial para ser transportado por el medio fluvial. Asimismo, genera otros interrogantes, basados en la sustancia de aquello que se exportó a través de los puertos entrerrianos, durante el período 1958-1983 y sus consecuencias económicas y sociales para la provincia.

Por último, sus puertos, aunque concentraron su actividad en una menor cantidad, superaron el efecto que produjo la conexión material mientras los navíos de ultramar se acercaron a sus dársenas. En la actualidad, y por otros motivos, el puerto de la provincia de Entre Ríos, desplazada de la hidrovía, se llama Rosario. 


\section{Fuentes}

Anuarios estadísticos de comercio exterior de la República Argentina. 1958-1983.

Anuarios de Comercio Exterior (1958-1983).

\section{Referencias bibliográficas}

Camarda, M. (2018). Una aproximación económica a los proyectos de conexión de Paraná con Santa Fe antes del túnel subfluvial. Revista de Estudios Maritimos y Sociales, 14, 178-193.

Cusmai, C. (2014). Aquellos Queridos Ferrys. Historia de los Ferrobarcos del rio Paraná. Galatea Ediciones.

Ferreira, G. H. (1970). Historia portuaria argentina. In FAEM (Ed.), Temas de Historia Marítima Argentina (pp. 271-286). Fundación Argentina de Estudios Marítimos.

Ferrer, A., \& Rougier, M. (2010). La historia de Zárate-Brazo Largo: Las dos caras del Estado argentino. FCE.

Fontana, J. (1997). Introducció a l'estudi de la història. Crítica.

Goularti Filho, A., \& Mateo, J. (2018). Infraestructura en transporte, políticas públicas, y modelos portuarios en países emergentes. Los puertos marítimos de Santa Catarina (Brasil) y fluviales de Entre Ríos (Argentina) entre modelos de acumulación. Revista de Estudios Marítimos y Sociales, 12, 94-126. https:// estudiosmaritimossociales.org/archivo/rems-12/filho-mateo-pdf/

Mateo, J. (2018). De la insularidad a la conectividad. Los puertos de Entre Ríos (Argentina) entre 1922 y 1983. In L. López Molina (Ed.), Cádiz al mundo: del floreciente siglo XVIII a los retos del Port of the future del siglo XXI (pp. 239271). Editorial Dykinson.

Mateo, J., \& Camarda, M. (2018). Las políticas públicas, el túnel y la conexión de la Megapotamia. Transporte y Territorio, 18, 222-245.

Mateo, J., \& Camarda, M. (2020). Un puente hasta el túnel entre Santa Fe y Paraná. Los intentos de conexión carretera de la mesopotamia argentina hasta su instalación definitiva en la agenda de las políticas públicas (1911-1960). In A. A. Nieto \& G. Yurkievich (Eds.), Los Espacios portuarios (en prensa). Agencia Nacional de Promoción Científica.

Taaffe, E. J., Morrill, R. L., \& Gould, P. R. (1963). TransportExpansion in Underdeveloped Countries: A Comparative Analysis. Geographical Review, 53(4), 503-529. 
Apéndice 1. Valores totales de las aduanas por puerto entrerriano y por año (1958- 1983)

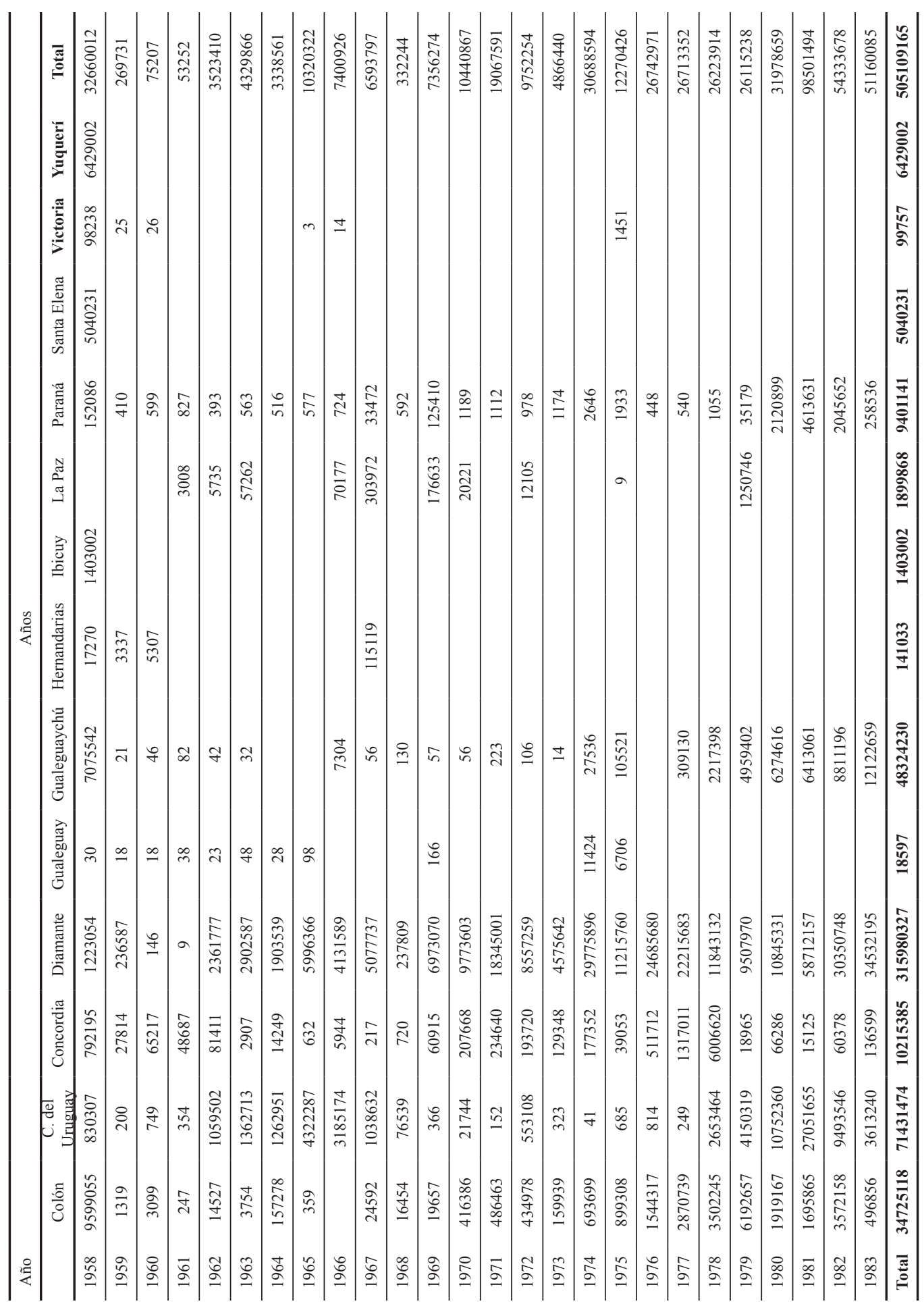

